\title{
Crystal Growth Kinetics of Calcite in a Dense Fluidized-Bed Crystallizer
}

\author{
Clifford Y. Tai, W.-C. Chien, and C.-Y. Chen \\ Dept. of Chemical Engineering, National Taiwan U niversity, Taipei, Taiwan 106
}

\begin{abstract}
The growth kinetics of calcite crystals are studied in a batch-fluidized-bed crystallizer, which is maintained at a constant $\mathrm{pH}$. The growth experiments are conducted in the metastable region explored as part of this research. The crystal growth rates are evaluated from the consumption rates of calcium ions, using the cured natural calcite or silica sand as seeding materials. Several operation variables are investigated, including supersaturation, $\mathrm{pH}$, ionic strength, superficial velocity, and particle size and type of seed. The significant factors that affect the crystal growth rate are identified. Then the crystal growth data of constant $\mathrm{pH}$ and ionic strength are analyzed by the two-step growth model. The mass-transfer coefficients are obtained and compared at various crystal sizes and superficial velocities. Finally, a growth-rate equation of calcite crystal, which is based on the two-step growth model, is proposed for design purposes.
\end{abstract}

\section{Introduction}

$R$ ecently a pellet reactor, which is a reactive, fluidized-bed, growth-type crystallizer, was developed for water softening, fluoride and phosphate removal, and heavy-metal recovery. The water feed and the chemical reagents required to cause deposition are fed to the reactor containing suspended seeds (Dirken et al., 1990; Seckler et al., 1990; van Dijk and Wilms, 1991). In water softening, the undesired species, calcium ion, reacts to form calcium carbonate and then grows on the seeds, which are later removed from the reactor after they exceed a certain size. In the operation of the pellet reactor the flow pattern in the fluidized bed resembles an ideal plug flow with a limited backmixing, which gives a higher conversion as compared to the ideal mix-flow reactor (Levenspiel, 1972). In the design of a pellet reactor for water softening, we need to know the crystal growth kinetics of calcium carbonate and the hydraulics of a fluidized bed. It seems that the former is less understood than the later. The reported growth-rate equation of calcium carbonate is rather empirical, for example, an overall growth-rate model (van Dijk and Wilms, 1991):

$$
\frac{\mathrm{d}\left[\mathrm{Ca}^{2+}\right]}{\mathrm{dt}}=\mathrm{K}_{\mathrm{T}} \mathrm{A}\left\{\left[\mathrm{Ca}^{2+}\right]\left[\mathrm{CO}_{3}^{2-}\right]-\mathrm{K}_{\mathrm{sp}}^{\prime}\right\}
$$

\footnotetext{
Correspondence concerning this article should be addressed to C. Y. Tai.
}

where $-\left(d\left[\mathrm{Ca}^{2+}\right] / d t\right)$ is the depletion rate of $\left[\mathrm{Ca}^{2+}\right]$ in the solution, which is the same as the crystal growth rate of $\mathrm{CaCO}_{3}$ in moles per unit time; $\mathrm{K}_{T}$ is a constant; $\mathrm{A}$ is the specific surface area of seed crystals; $K_{s p}^{\prime}$ is the concentration solubility product of calcite; and $\left\{\left[\mathrm{Ca}^{2+}\right]\left[\mathrm{CO}_{3}{ }^{2-}\right]-\mathrm{K}_{\mathrm{sp}}^{\prime}\right\}$ represents the driving force for crystal growth.

Several mechanisms regarding crystal growth have been proposed in the literature (Mullin, 1993), among which the two-step growth model is considered the most useful from the chemical engineering point of view. At steady-state conditions, the two steps can be described mathematically by the following equations:

$$
\begin{aligned}
\mathrm{G} & =\mathrm{K}_{\mathrm{d}}\left(\sigma-\sigma_{\mathrm{i}}\right) & & \text { mass transfer } \\
& =\mathrm{K}_{\mathrm{r}} \sigma_{\mathrm{i}}{ }^{\mathrm{r}} & & \text { surface reaction. }
\end{aligned}
$$

A though this model is a simplified scheme for crystal growth, it reveals a great deal of useful kinetic information, which was recently summarized by Tai (1997). The systems studied are mostly soluble salts using seeded techniques. Similar studies of sparingly soluble salts are limited, because large single-seed crystals of the system are difficult to prepare and the application of the technique was limited in the past.

The single-seed crystals of calcite, one of the barely soluble salts, were successfully prepared by using the gel growth 
technique, and the crystal growth kinetics of calcite grown in a stirred vessel was investigated using the two-step growth model to analyze the growth-rate data (Tai et al., 1993). It is concluded that the mass-transfer resistance and surface-reaction resistance are significant. The mass-transfer resistance is related to the relative velocity between crystal and solution and increases with a decrease in relative velocity. U nder the well-suspended conditions, the relative velocity between crystal and solution in a fluidized bed is lower than that in a stirred vessel, thus the mass-transfer resistance as well as the surface-reaction resistance for crystal growth of calcite should be considered in a fluidized bed. Therefore, an overall growth-rate equation, such as Eq. 1, is not an adequate expression for scale-up purposes, because different hydrodynamic behaviors exist between scales.

Besides the hydrodynamic effects, the crystal growth of barely soluble salts are affected by the chemical properties of the supersaturated solution. For example, Stubicar et al. $(1990,1992)$ found that the solution properties, including ionic strength, $\mathrm{pH}$, and lead-to-fluoride ion activity ratio, influenced the crystal growth kinetics of lead fluoride; $\alpha-\mathrm{PbF}_{2}$ and $\beta-\mathrm{PbF}_{2}$ appeared at different $\mathrm{pH}$ values, and crystal growth rates were higher at higher ionic strength.

The aim of this study is to investigate the crystal growth kinetics of calcite in a dense fluidized-bed crystallizer using the $\mathrm{pH}$-stat method. Experiments were first conducted in a $\mathrm{pH}$-stat vessel to identify the metastable region, where nucleation is suppressed, for the $\mathrm{CaCl}_{2}-\mathrm{Na}_{2} \mathrm{CO}_{3}-\mathrm{H}_{2} \mathrm{O}$ system. Then the growth experiments were performed in the metastable region using three crystal sizes, namely 460, 650, and $920 \mu \mathrm{m}$, which are prepared by sieving the cured natural calcite. The crystal size is the mean size of the apertures of the two closest ASTM standard sieves. For example, crystals of size $460 \mu \mathrm{m}$ means the fraction of crystals retained between A STM sieves Nos. 40 and 35, with nominal apertures of 420 and $500 \mu \mathrm{m}$, respectively. The crystal growth rate was evaluated from the depletion rate of $\left[\mathrm{Ca}^{2+}\right]$ in the solution. The growth-rate data were then interpreted in terms of the two-step growth model, thus the mass-transfer coefficient and surface-reaction coefficient were determined. The effects of operating variables, such as ionic strength, $\mathrm{pH}$, superficial velocity, crystal size, and seed type, were explored. The obtained crystal growth-rate data will serve as the design basis of a pellet reactor for water softening.

\section{Experimental Procedure \\ Determination of relative supersaturation}

The expression of the driving force used for crystal growth of barely soluble salts is the relative supersaturation proposed by $\mathrm{N}$ ielsen and Toft (1984):

$$
\sigma=\left(\mathrm{K}_{\mathrm{ip}} / \mathrm{K}_{\mathrm{sp}}\right)^{1 / 2}-1
$$

where $K_{i p}$ is the ionic product, defined as $K_{i p}=a_{\mathrm{Ca}^{2+}}$.

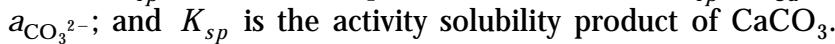
The activity of species, $\mathrm{a}_{\mathrm{Ca}^{2+}}$ or $\mathrm{a}_{\mathrm{CO}_{3}{ }^{2-}}$, is the product of the activity coefficient and the concentration of the respective species. The concentrations of ionic species were computed from the measured $\mathrm{pH}$, total calcium concentration, and total

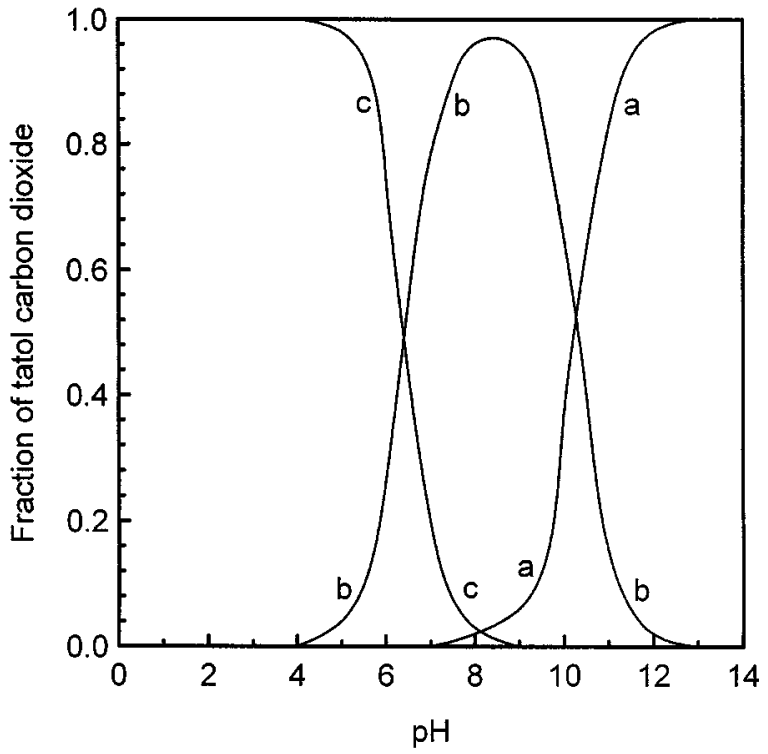

Figure 1. Fraction of total $\mathrm{CO}_{2}$ present as the respective ions at various hydrogen-ion concentration: (a) $\mathrm{CO}_{3}{ }^{2-}$; (b) $\mathrm{HCO}_{3}{ }^{-}$; (c) $\mathrm{H}_{2} \mathrm{CO}_{3}$ (ASTM, 1994).

carbonate concentration by successive approximation for the ionic strength, using a computer program that contains mass-action equations, mass balance equations, charge-balance equations, and the modified D ebye-H ückel equation for calculating the activity coefficient (N ancollas, 1996; Tai et al., 1993). In the operation of a pellet reactor, supersaturation should be controlled in a suitable range; a low supersaturation gives a low growth rate, which means a low removal rate of species, and a high supersaturation causes nucleation, which messes up the operation. The supersaturation is related to the concentration of $\mathrm{CO}_{3}{ }^{2-}$, which is a function of $\mathrm{pH}$ at a fixed concentration of total carbonate. Therefore, as judged from Figure 1, which is a diagram showing the fraction of total carbon dioxide present as the respective ions at various pHs (ASTM , 1974), a suitable operational range of $\mathrm{pH}$ is roughly between 8.5 and 10.5 , a $\mathrm{pH}$ lower than 8.5 giving a low $\mathrm{CO}_{3}{ }^{2-}$ concentration and a $\mathrm{pH}$ higher than 10.5 absorbing too much $\mathrm{CO}_{2}$ from air. The effect of $\mathrm{pH}$ on the relative supersaturation, which is obtained by computing, is clearly shown in Figure 2. It means that the control of $\mathrm{pH}$ is important in the experiment of studying the crystallization kinetics of $\mathrm{CaCO}_{3}$.

\section{I dentification of metastable region of calcite}

A key to the successful operation of pellet reactor is good control of supersaturation, which is generated by the chemical reaction. To suppress nucleation of calcite in growth experiments, supersaturation should be kept in the metastable region, which is the area between supersolubility and solubility curves (Nielsen and Toft, 1984). Since the supersolubility curve of the $\mathrm{CaCl}_{2}-\mathrm{Na}_{2} \mathrm{CO}_{3}-\mathrm{H}_{2} \mathrm{O}$ system is not available, experiments were first performed to identify the metastable region. Under constant temperature $\left(25^{\circ} \mathrm{C}\right)$ and constant $\mathrm{pH}$ 


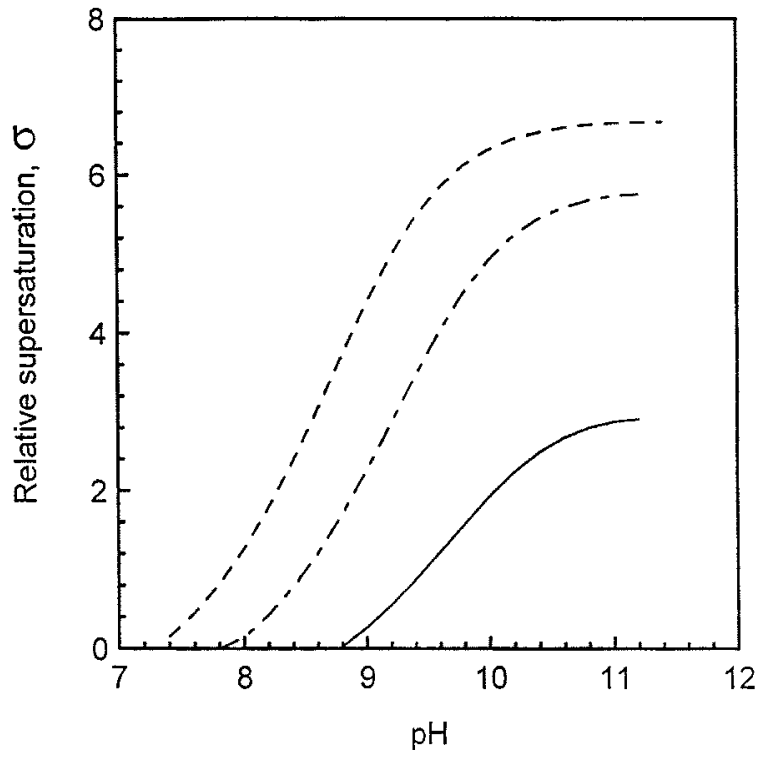

Figure 2. Relative supersaturation of calcium carbonate salt as a function of $\mathrm{pH}: \mathrm{T}=25^{\circ} \mathrm{C}$ and $[\mathrm{Ca}]_{\mathrm{T}}=$ $0.0005 \mathrm{kmol} / \mathrm{m}^{3}$.

$\left.---\left[\mathrm{CO}_{3}\right]_{\mathrm{T}}=0.05 \mathrm{kmol} / \mathrm{m}^{3} ;-\cdot-\overline{\mathrm{kmol}} / \mathrm{m}^{3} ;-\left[\mathrm{CO}_{3}\right]_{T}=0.005\right]_{T}=0.0005 \mathrm{kmol} / \mathrm{m}^{3}$.

(8.5, 9.5, and 10.5, respectively), $100 \mathrm{~mL}$ of $\mathrm{CaCl}_{2}$ and $\mathrm{Na}_{2} \mathrm{CO}_{3}$ solutions were mixed and stirred for $2 \mathrm{~h}$. F or a specific concentration of calcium chloride, the solution remained clear at a low concentration of sodium carbonate. When the concentration of $\mathrm{Na}_{2} \mathrm{CO}_{3}$ increased, the solution became turbid due to nucleation. The boundaries were recorded for various $\mathrm{CaCl}_{2}$ concentrations, such as those shown in Table 1 for a $\mathrm{pH}$ of 8.5. Then the concentrations or activities of $\mathrm{Ca}^{2+}$ and $\mathrm{CO}_{3}{ }^{2-}$ at the boundaries were calculated using the same computer program as was used for estimating supersaturation. Finally, the metastable region was constructed and all the growth experiments were performed in this region.

\section{Crystallization system}

The crystallization system, containing a $\mathrm{pH}$-stat fluidizedbed crystallizer, a storage tank, and a pH control system, as shown in Figure 3, was used to measure the growth rate of calcite crystal. The main part of the fluidized-bed crystallizer is a PVC column with a distributor at the bottom. Immediately above the column is an enlarged section to prevent seed crystals from carrying over to the storage tank. A supersaturated solution, which was prepared by mixing $\mathrm{CaCl}_{2}$ and $\mathrm{Na}_{2} \mathrm{CO}_{3}$ solutions, of $6 \mathrm{~L}$ with a desired $\mathrm{pH}$ was charged into the storage tank and another $0.5 \mathrm{~L}$ of the same solution was fed into the fluidized bed. The solution in the storage tank was then pumped through a distributor and into the fluidized bed. A fter that, the solution overflowed to the storage tank. When the flow rate and $\mathrm{pH}$ became steady, the pump was stopped and approximately $25 \mathrm{~g}$ of seed crystals were introduced into the crystallizer. The pump was restarted and the growth experiment began. The $\mathrm{pH}$ of the solution was maintained constant during the operation, using a $\mathrm{pH}$-stat appara-
Table 1. Demarcation of M etastable Region for Calcium Carbonate $\left(\mathrm{CaCO}_{3}\right)$ at $\mathrm{pH}=8.5$ and $\mathrm{T}=25^{\circ} \mathrm{C}$

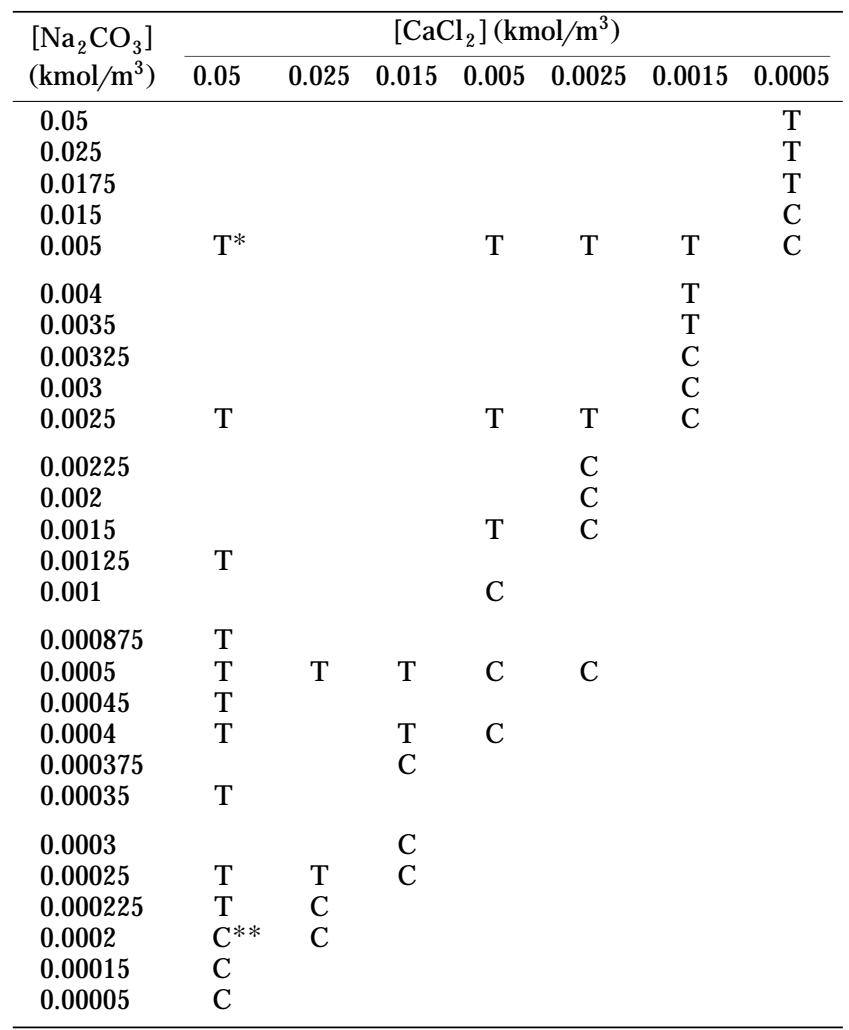

$*_{T}$ means turbid.

**C means clear.

tus to control the amount of $\mathrm{NaOH}$ solution added to the storage tank. A 3-mL sample of the solution was withdrawn from the crystallizer every 30 min by a syringe fitted with a

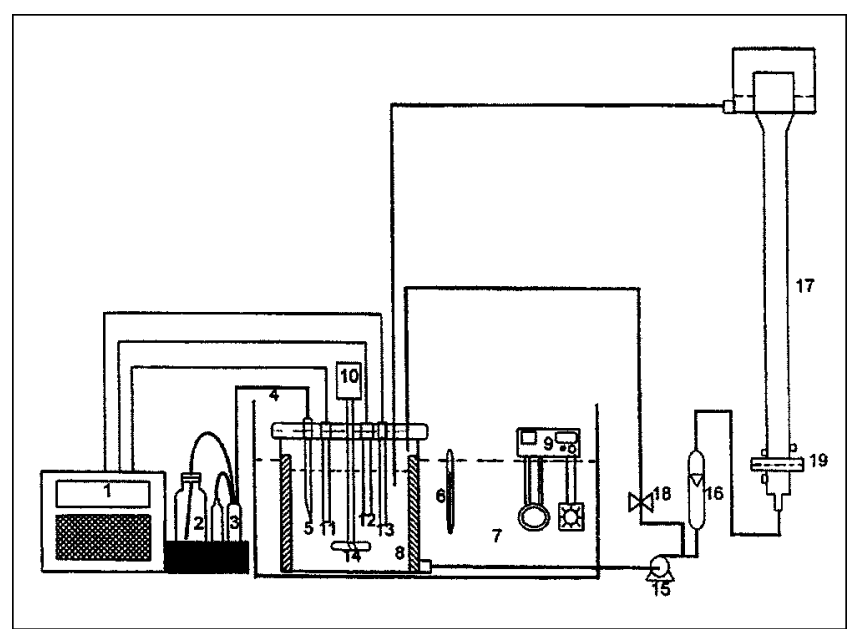

Figure 3. PH-stat crystallization system.

1. $\mathrm{pH}$ and temperature indicator; 2 . reagent bottle; 3 . pumping system of reagent; 4 . reagent delivering line; 5 . burette; 6. thermometer; 7 . water bath; 8 . storage tank; 9 . temperature controller; 10. motor; 11. glass-electrode; 12. reference electrode; 13 . thermocompensator; 14 . axial-flow impeller; 15. magnetic motor; 16. flowmeter; 17 . fluidized-bed crystallizer; 18. recycle valve; 19. distributor. 
$0.22-\mu \mathrm{m}$ filter and then diluted to $50 \mathrm{~mL}$ with deionized water. The calcium-ion concentration of the diluted solution was then determined by an atomic absorption spectrometer and the growth rate of calcite crystal was estimated from the consumption rate of the calcium ion. A typical run lasted 260 $\min$.

\section{Determination of crystal growth rate}

The total mass and surface area of crystals are given by

$$
\begin{gathered}
\mathrm{W}=\mathrm{n} \rho_{\mathrm{p}} \alpha \mathrm{L}^{3} \\
\mathrm{~A}=\mathrm{n} \beta \mathrm{L}^{2},
\end{gathered}
$$

where $\rho_{\mathrm{p}}$ is the crystal density; $\alpha$ and $\beta$ are the volume and surface area shape factor, respectively; and $n$ the number of crystals.

The crystal growth rate expressed in $\mathrm{kg} / \mathrm{m}^{2} \mathrm{~s}$ is

$$
R_{g}=\frac{1}{A} \frac{d W}{d t}
$$

or

$$
\mathrm{R}_{\mathrm{g}}=\frac{3 \alpha \rho_{\mathrm{p}}}{\beta} \frac{\mathrm{dL}}{\mathrm{dt}}
$$

Combine Eqs. 7 and 8, the linear growth rate $G$ can be written as

$$
\mathrm{G}=\frac{\mathrm{dL}}{\mathrm{dt}}=\frac{\beta}{3 \alpha \rho_{\mathrm{p}} \mathrm{A}} \frac{\mathrm{dW}}{\mathrm{dt}} .
$$

During a growth experiment, the change of crystal mass in a

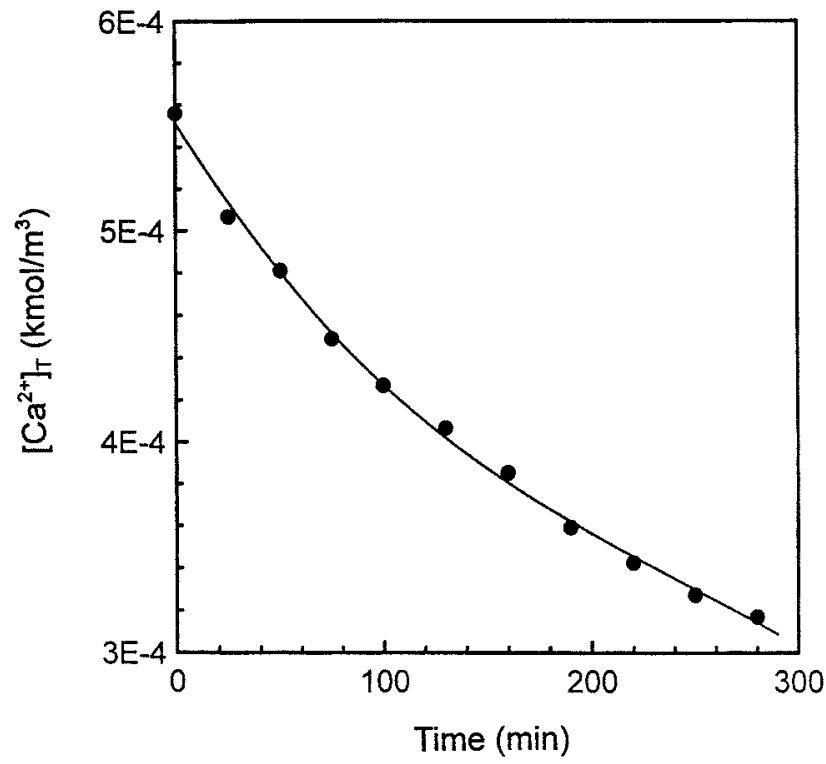

Figure 4. Typical change in the total calcium concentration over time for run 014 . crystallizer is related to the change of calcium-ion concentration as follows:

$$
\frac{d W}{d t}=M V\left(\frac{-d\left[C \mathrm{Ca}^{2+}\right]}{d t}\right)
$$

where $\mathrm{M}$ is the molecular weight of $\mathrm{CaCO}_{3}$, and $\mathrm{V}$ is the solution volume.

Equation 10 is substituted into $\mathrm{Eq} .9$ to give

$$
\mathrm{G}=\frac{\beta \mathrm{MV}}{3 \alpha \rho_{\mathrm{p}} \mathrm{A}}\left(-\frac{\mathrm{d}\left[\mathrm{Ca}^{2+}\right]}{\mathrm{dt}}\right)
$$

Combining Eqs. 5 and 6, we have

$$
\frac{\beta}{\alpha \mathrm{A}}=\frac{\mathrm{L} \rho_{\mathrm{p}}}{\mathrm{W}} .
$$

Substituting Eq. 12 into Eq. 11, we obtain the linear growthrate expression:

$$
G=\frac{L M V}{3 W}\left(-\frac{d\left[C \mathrm{a}^{2+}\right]}{d t}\right)
$$

Once the concentration profile of $\left[\mathrm{Ca}^{2+}\right]$, which is determined by an atomic absorption spectrometer, is available, the linear crystal growth rate can be evaluated by assuming that the crystal size and total crystal weight are the same as for the seed crystal. This assumption will not cause much error because the total increase in crystal size or weight is negligible as compared with the seed crystal. For example, the growth rate of calcite is roughly $1 \times 10^{-10} \mathrm{~m} / \mathrm{s}$, and thus an increase in crystal size for a growth time of $260 \mathrm{~min}$ is estimated to be $1.5 \mu \mathrm{m}$, which is negligible when compared with the seed sizes of $460 \mu \mathrm{m}$ or larger. A typical calcium-ion concentration profile trend is shown in Figure 4.

\section{Results and Discussion \\ Metastable region of $\mathrm{CaCl}_{2}-\mathrm{Na}_{2} \mathrm{CO}_{3}-\mathrm{H}_{2} \mathrm{O}$ system}

$\mathrm{U}$ sing the concentration data at the boundary shown in Table 1 for $\mathrm{pH}$ at 8.5 and other similar data for $\mathrm{pH}$ at 9.5 and 10.5 not shown here (Chen, 1985), $\mathrm{p}[\mathrm{Ca}]_{\mathrm{T}}$ is plotted against $\mathrm{p}\left[\mathrm{CO}_{3}\right]_{T}$ in Figure 5 to mark the supersolubility curves, in which $\mathrm{p}[\mathrm{Ca}]_{T}$ and $\mathrm{p}\left[\mathrm{CO}_{3}\right]_{T}$ represent $-\log [\mathrm{Ca}]_{T}$ and $-\log \left[\mathrm{CO}_{3}\right]_{T}$, respectively. The solubility curves are also plotted in the figure using the solubility product of $\mathrm{CaCO}_{3}$. The metastable regions of the three $\mathrm{pHs}$ do not agree when they are projected to the same $\mathrm{pH}$ plane. However, if $\left[\mathrm{Ca}^{2+}\right]$ and $\left[\mathrm{CO}_{3}{ }^{2-}\right]$ at the boundaries, which were calculated from the total concentration data using a computer program for estimating supersaturation, are used in the plotting (as shown in Figure 6), the metastable region is independent of the $\mathrm{pH}$ value, and the solubility and supersolubility curves are bent at both ends. Similar curves for the $\mathrm{CaCl}_{2}-\mathrm{Na}_{3} \mathrm{PO}_{4}-\mathrm{H}_{2} \mathrm{O}$ system have been reported (Füredi-M ilhofer et al., 1975). This type of curve means that the formation of complex ions is significant (Söhnel and G arside, 1992). When the concentra- 


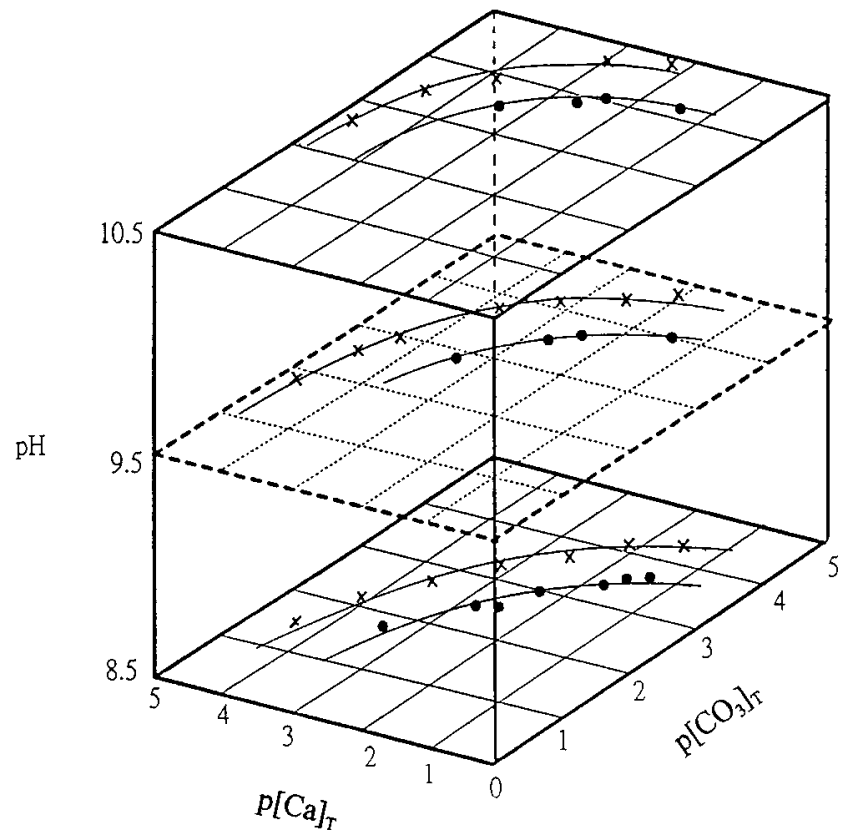

Figure 5. Metastable region of calcium carbonate for the $\mathrm{CaCl}_{2}-\mathrm{Na}_{2} \mathrm{CO}_{3}$ system at $\mathrm{pH} 8.5,9.5$, and 10.5.

$-\times-$ supersolubility curve; $-\cdot-$ solubility curve.

tion of $\mathrm{Ca}^{2+}$ and $\mathrm{CO}_{3}{ }^{2-}$, that is, $\left[\mathrm{Ca}^{2+}\right]$ and $\left[\mathrm{CO}_{3}{ }^{2-}\right]$, in Figure 6 is replaced by the activity of the respective ion, $\mathrm{a}_{\mathrm{Ca}^{2+}}$

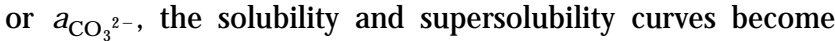
almost straight and parallel lines in the concentration range studied in this experiment, as shown in Figure 7. This simplifies the plotting of the metastable region.

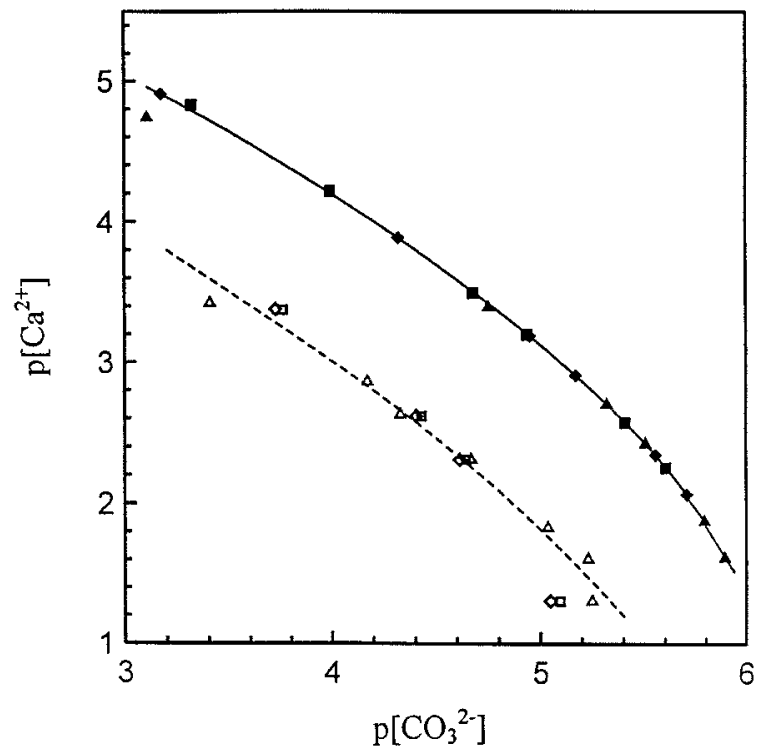

Figure 6. $\mathrm{p}\left[\mathrm{Ca}^{2+}\right]$ vs. $\mathrm{p}\left[\mathrm{CO}_{3}{ }^{2-}\right]$ : metastable region of calcium carbonate.

- solubility curve: $\Delta \mathrm{pH}=8.5, \diamond \mathrm{pH}=9.5, \boldsymbol{\mathrm { pH }}=$ 10.5; -- - supersolubility curve: $\Delta \mathrm{pH}=8.5, \diamond \mathrm{pH}=9.5$ $\square \mathrm{pH}=10.5$.

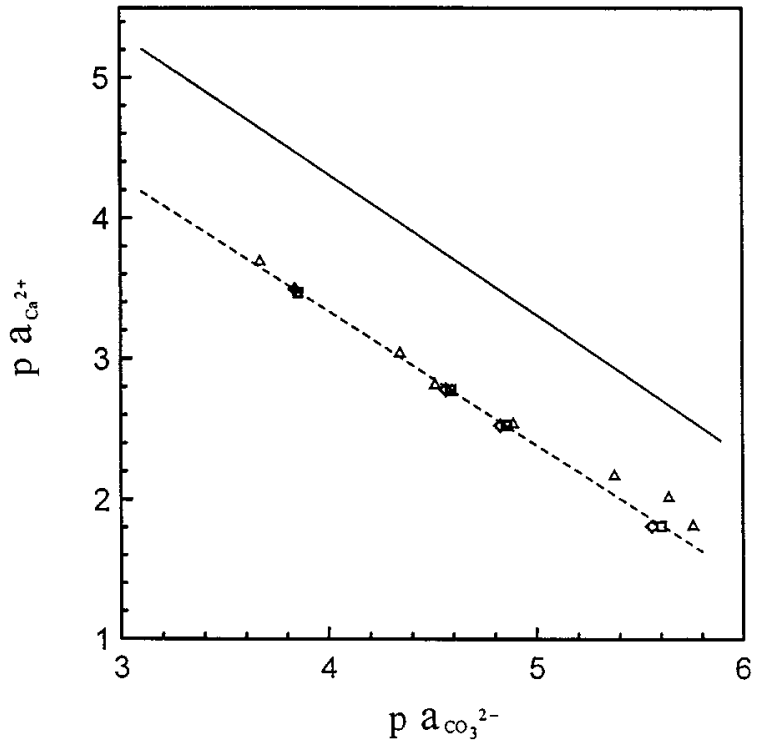

Figure 7. $\mathrm{pa}_{\mathrm{Ca}^{2+}}$ vs. $\mathrm{pa}_{\mathrm{CO}_{3}}{ }^{2-}$ : metastable region of calcium carbonate.

- solubility curve; - - - supersolubility curve: $\Delta \mathrm{pH}=$ 8.5, $\diamond \mathrm{pH}=9.5, \square \mathrm{pH}=10.5$.

\section{Factors affecting calcite growth rate in a dense fluidized bed}

In the operation of a fluidized bed, the superficial velocity of the crystals should be lower than the terminal velocity, otherwise, the crystals would be carried over the top of the bed. A t low superficial velocity, a boundary between solution and suspension is clearly observed in a dense bed. When the superficial velocity approaches the terminal velocity, particles move freely in the bed and the boundary no longer exists. In this case, it is called a lean fluidized bed. The dense bed is more advantageous as far as seed loading is concerned. Therefore, factors that affect the calcite growth rate in a dense bed are investigated, including supersaturation, $\mathrm{pH}$, ionic strength, superficial velocity, particle size, and type of seeds.

Figure 8 shows the calcite growth rate as a function of supersaturation at various levels of ionic strength from 0.0025 to $0.0340 \mathrm{kmol} / \mathrm{m}^{3}$. For all levels of ionic strength, which is adjusted by adding $\mathrm{NaCl}$ solution, the growth rates increase with an increase in supersaturation. At the same supersaturation, the groth rates increase with ionic strength from 0.0025 $\mathrm{kmol} / \mathrm{m}^{3}$ to $0.0185 \mathrm{kmol} / \mathrm{m}^{3}$; however, a further increase in ionic strength is no longer effective. Besides, the effect of ionic strength is less significant at higher supersaturations. One other thing worth noting is that the slope of the line, $\log G$ vs. $\log \sigma$, changes for the lowest ionic strength of 0.0025 $\mathrm{kmol} / \mathrm{m}^{3}$, implying a change in the strength of various types of resistance to crystal growth. The effects of ionic strength have been reported for the crystal growth of vaterite and lead fluoride. Kralj et al. (1990) found a 10\% increase in the growth rate of vaterite crystal when the ionic strength varied between $0.015 \mathrm{kmol} / \mathrm{m}^{3}$ and $0.315 \mathrm{kmol} / \mathrm{m}^{3}$. A s compared with the range studied in this experiment $\left(0.0185 \mathrm{kmol} / \mathrm{m}^{3}\right.$ to 0.034 $\mathrm{kmol} / \mathrm{m}^{3}$ ), the effect of ionic strength was not observed. O n the other hand, Stubicar et al. (1993) reported that the growth 


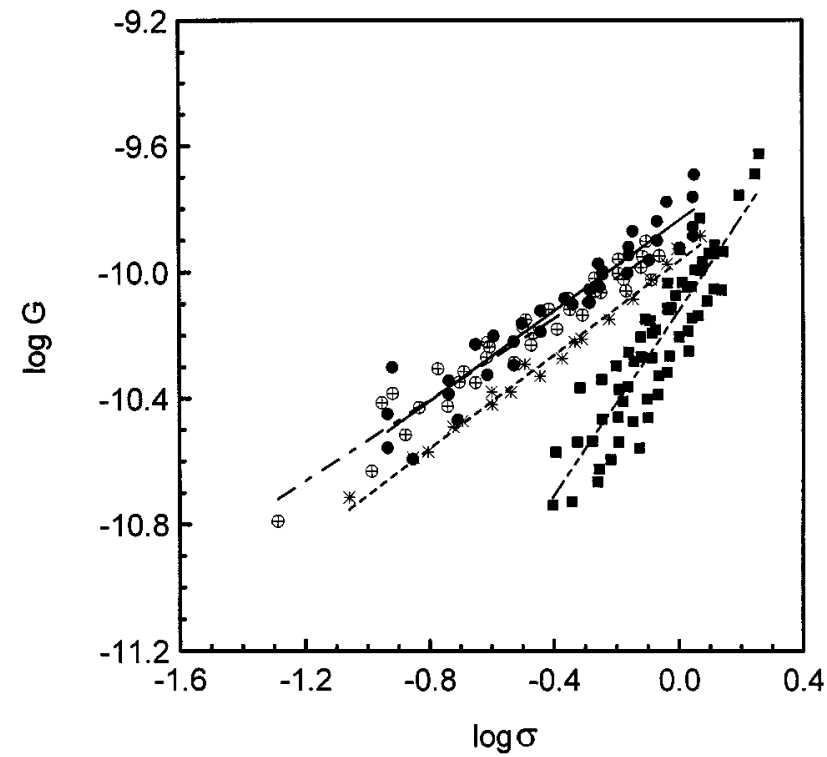

Figure 8. $\log G$ vs. $\log \sigma$ effect of ionic strength on the growth rate of $\mathrm{CaCO}_{3}$ crystal at $\mathrm{L}=460 \mu \mathrm{m}$, $\mathbf{p H}=9.5, \mathrm{~T}=25^{\circ} \mathrm{C}$.

$\oplus \mathrm{I}=0.0340 \mathrm{kmol} / \mathrm{m}^{3} ; \bullet \mathrm{I}=0.0185 \mathrm{kmol} / \mathrm{m}^{3} ; * \mathrm{I}=0.0105$ $\mathrm{kmol} / \mathrm{m}^{3} ;$ - I $=0.0025 \mathrm{kmol} / \mathrm{m}^{3}$.

rate of $\mathrm{PbF}_{2}$ is about five times greater at a high ionic strength of $0.1 \mathrm{kmol} / \mathrm{m}^{3}$ as compared with that in water, and a different growth mechanism is speculated. All the findings on the effect of ionic strength are similar to the results of this experiment.

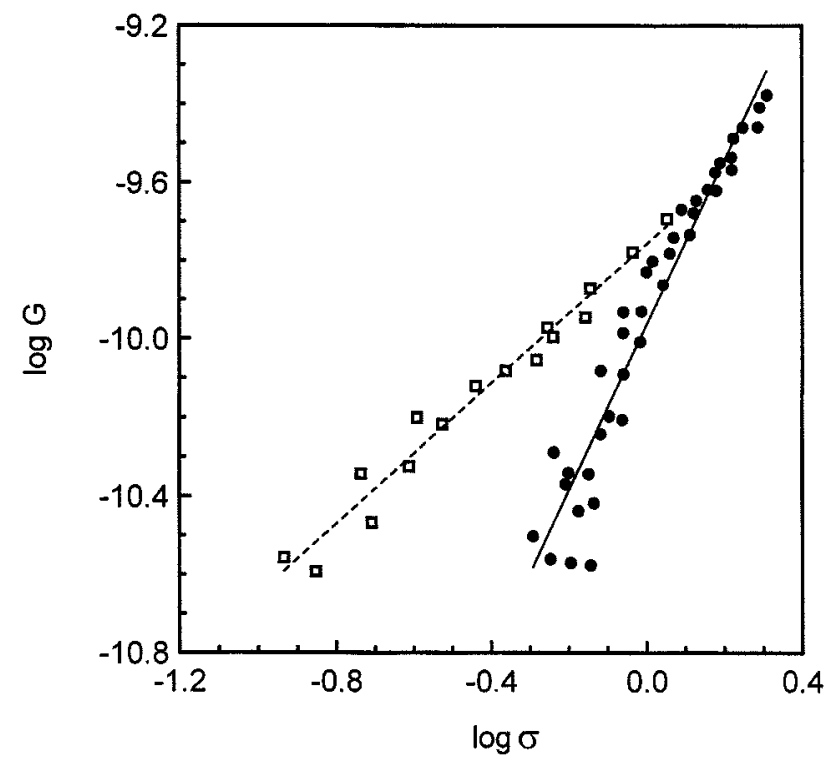

Figure 9. Crystal growth rates of calcium carbonate, $\log \mathrm{G}$ vs. $\log \sigma$, at two $\mathrm{pH}$ values: $\mathrm{I}=\mathbf{0 . 0 1 8}$ $\mathrm{kmol} / \mathrm{m}^{3} ; \mathrm{L}=460 \mu \mathrm{m} ; \mathrm{T}=25^{\circ} \mathrm{C} ; \mathrm{u}=2.36 \times$ $10^{-2} \mathrm{~m} / \mathrm{s}$.

- $\mathrm{pH}=8.5 ; \square \mathrm{pH}=9.5$.
The effects of $\mathrm{pH}$ on the growth rate of calcite are shown in Figure 9 for two levels of $\mathrm{pH}$, namely 8.5 and 9.5, which is about the range used in a pellet reactor for water softening (van Dijk and Wilms, 1991). Similar to the effects of ionic strength, different slopes of the $\log G-\log \sigma$ plot are obtained at different $\mathrm{pH}$, and the effects of $\mathrm{pH}$ diminish at higher supersaturations. It is possible that the main resistance to crystal growth is influenced by ionic strength and $\mathrm{pH}$ in the same way. The effects of $\mathrm{pH}$ on the growth rate of lead fluoride were studied by Stubicar et al. (1993), using the constant-composition method. The result is consistent with that of calcite crystal studied in this experiment, that is, the crystal growth rate increases with $\mathrm{pH}$ when the $\mathrm{pH}$ is lower than the isoelectric point, which is $9 \sim 10$ and 5.6 for calcite (R eed, 1989) and $\alpha$-lead fluoride, respectively.

The growth rates of calcite were measured at various superficial velocities, that is, $1.42,2.36,3.54$ and $4.72 \mathrm{~m} / \mathrm{s}$, for the seed crystals of size $460-\mu \mathrm{m}$. A lthough the bed voidage and bed expansion changes a great deal, the calcite growth rates are rather constant, as shown in Figure 10. A ssuming that the solution velocity does not influence the surface-reaction step, the constant growth rate is consistent with Tournie et al.'s (1979) conclusion that the mass-transfer coefficient is practically independent of the liquid velocity, which they arrived at by analyzing the extensive dissolution data for both lean and dense fluidized beds reported in the literature. On the other hand, Figure 11 shows the effects of particle size on the calcite growth rate at a superficial velocity of $4.72 \mathrm{~m} / \mathrm{s}$. The calcite growth rate increases with an increase in crystal size. The influence of superficial velocity and crystal size on the mass-transfer coefficient in a fluidized bed is discussed later.

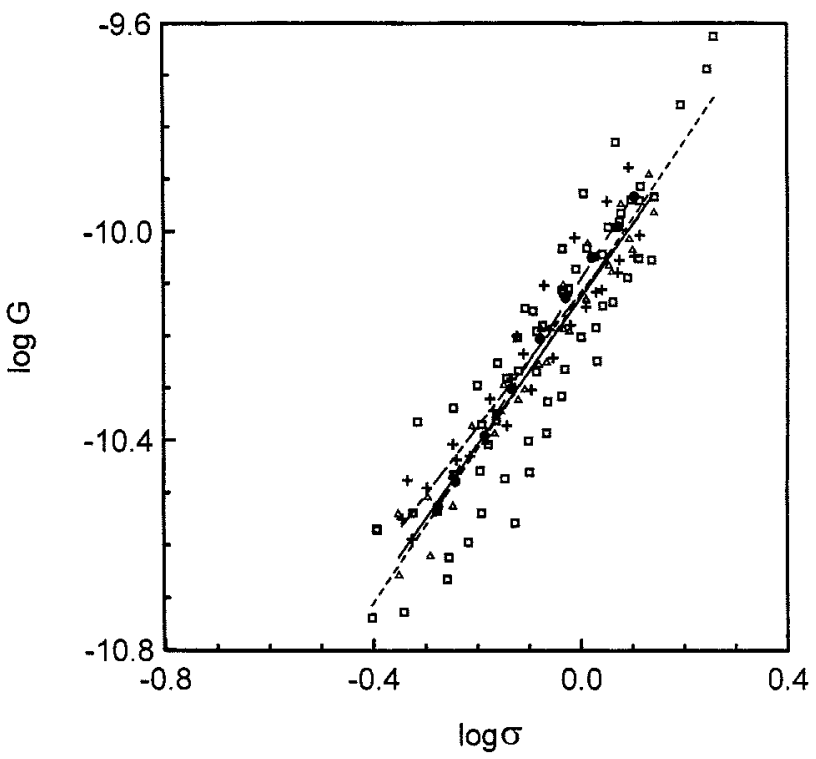

Figure 10. Growth rates of calcium carbonate, $\log G$ vs. $\log \sigma$, at various superficial velocities: $\mathbf{L}=$ $460 \mu \mathrm{m} ; \mathrm{pH}=9.5 ; \mathrm{T}=25^{\circ} \mathrm{C} ; \mathrm{I}=0.0025 \mathrm{kmol}$ $/ \mathrm{m}^{3}$.

$\Delta \mathrm{u}=1.42 \mathrm{~m} / \mathrm{s} ; \square \mathrm{u}=2.36 \mathrm{~m} / \mathrm{s} ;+\mathrm{u}=3.54 \mathrm{~m} / \mathrm{s} ; \bullet \mathrm{u}=$ $4.72 \mathrm{~m} / \mathrm{s}$. 


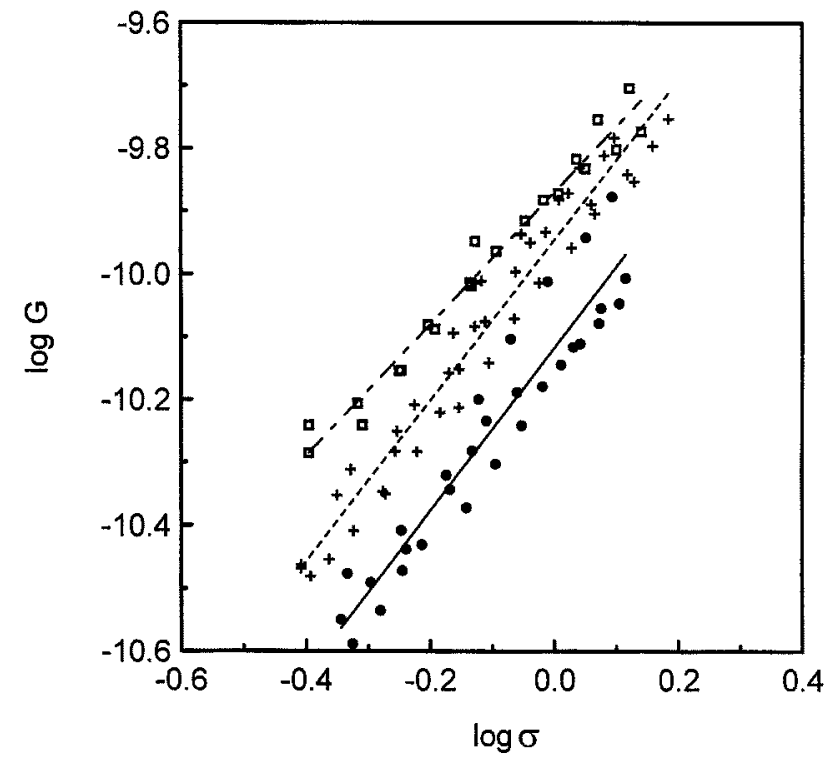

Figure 11. $\log \mathrm{G}$ vs. $\log \sigma$ effect of crystal size at $\mathrm{pH}=$ $9.5 ; \mathrm{I}=0.0025 \mathrm{kmol} / \mathrm{m}^{3} ; \mathrm{u}=4.72 \mathrm{~m} / \mathrm{s} ; \mathrm{T}=$ $25^{\circ} \mathrm{C}$.

$\square \mathrm{L}=920 \mu \mathrm{m} ;+\mathrm{L}=650 \mu \mathrm{m} ; \bigcirc \mathrm{L}=460 \mu \mathrm{m}$.

In the operation of a water-softening pellet reactor, silica sand or quartz sand is used as the seeding material (van Dijk and Wilms, 1991). It is therefore desirable to investigate the growth phenomena of calcite on the surface of silica sand. The concentration profile of the calcium ion is shown in Figure 12 for an experimental run using silica sand as seed. When compared with Figure 4, it is clearly seen that an induction time of calcite growth is required for silica sand. The induc-

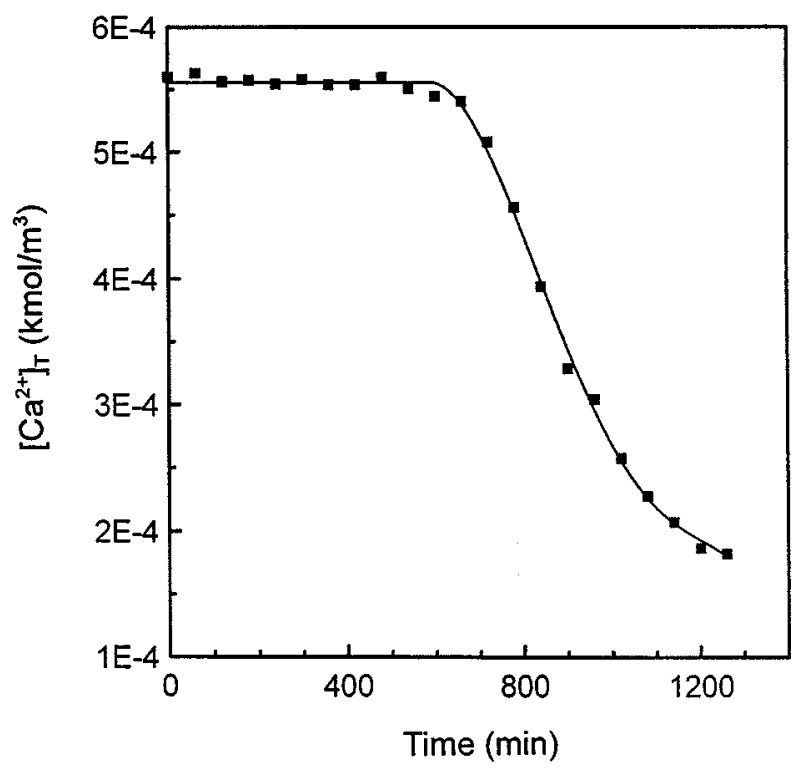

Figure 12. Induction time for calcium carbonate growth using silica sand as seed under the following operation conditions: $\mathrm{pH}=9.5 ; \mathrm{u}=\mathbf{2 . 3 6}$ $\mathrm{m} / \mathrm{s} ; \sigma=1.3 ; \mathrm{L}=460 \mu \mathrm{m}$. tion time is $600 \mathrm{~min}$ for the specific operating conditions, and is shorter at higher supersaturation. The calcite growth rate on the silica sand seed is lower than that on the calcite seed, as shown in Figure 13, in which curves $A$ and $B$ are the growth rates of sand seed after a growth period of $15 \mathrm{~h}$ and $20 \mathrm{~h}$, respectively. The growth rate of sand seed will eventually approach the growth rate of calcite seed when the surface of sand seed is fully covered with calcite.

\section{M ass-transfer coefficient of calcite growth in a dense fluidized bed}

According to two different sources summarized by Tai et al. (1993), the surface reaction order of calcite growth is approximately 2 . This is also true for some other systems, such as copper sulfate pentahydrate (Tai and Pan, 1985) and potassium alum (Tai et al., 1987). Taking $r=2$, Eqs. 2 and 3 are combined to give

$$
\frac{\sigma}{\sqrt{\mathrm{G}}}=\frac{1}{\mathrm{~K}_{\mathrm{d}}} \sqrt{\mathrm{G}}+\frac{1}{\sqrt{\mathrm{K}_{\mathrm{r}}}} .
$$

Thus the mass-transfer coefficient, $\mathrm{K}_{\mathrm{d}}$, can be evaluated from the slope of the plot, $(\sigma / \sqrt{G})$ vs. $\sqrt{G}$. Figure 14 illustrates the plotting of Eq. 14 for three different crystal sizes at the same $\mathrm{pH}$ and ionic strength. The obtained $\mathrm{K}_{\mathrm{d}}$ are listed in Table 2 . $U$ sing the table, we can compare $K_{d}$ for the different crystal sizes suspended at a superficial velocity of 3.54 $\mathrm{m} / \mathrm{s}$ during the first three runs. On the other hand, the $K_{d}$ values of the $460-\mu \mathrm{m}$-sized crystals operated at various superficial velocities can be compared using the last three rows in the table. D espite the variation in particle size and superficial velocity, the $\mathrm{K}_{\mathrm{d}}$ are rather constant. The deviations from the average value of $K_{d}, 1.32 \times 10^{-10}$, are less than $10 \%$.

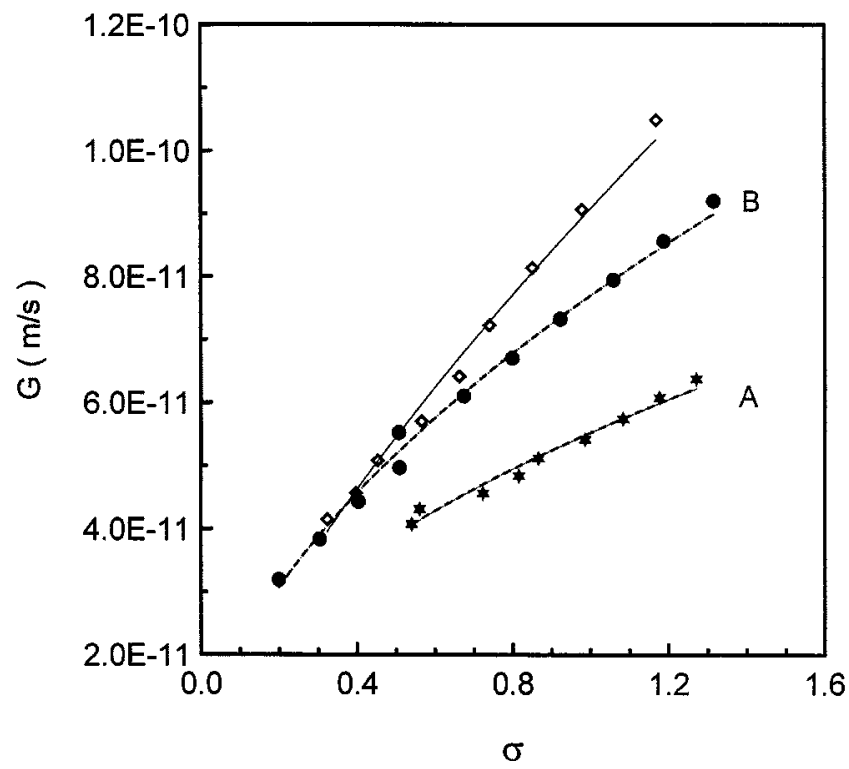

Figure 13. Comparison of growth rates of different seed types.

$\diamond$ calcite; silica sand after $20 \mathrm{~h}$ of growth time; $\star$ silica sand after $15 \mathrm{~h}$ of growth time. 


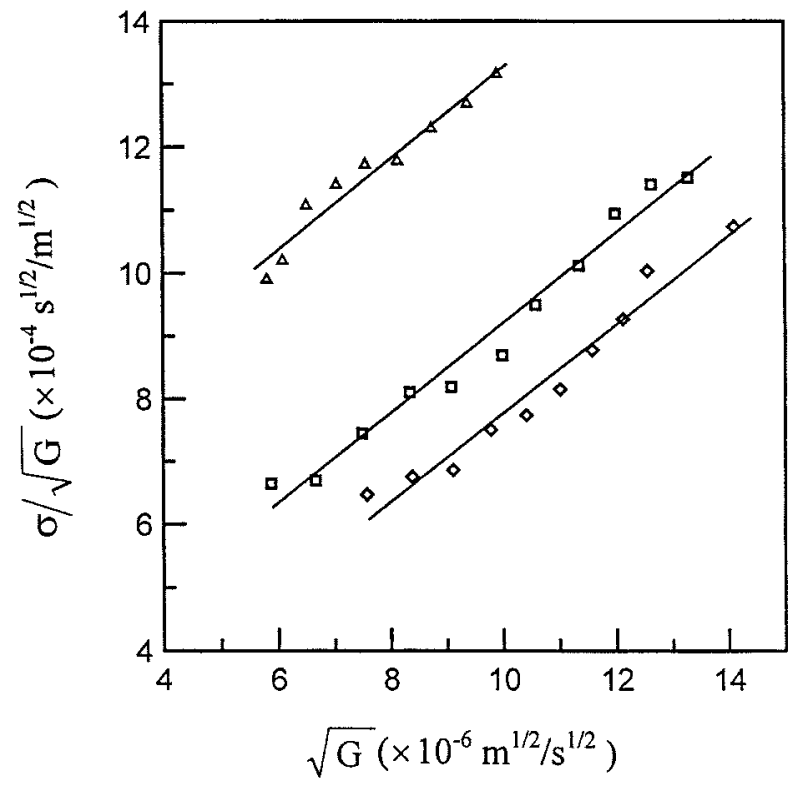

Figure 14. Equation 14 for calcium carbonate system at $\mathrm{pH}=9.5$ and $\mathrm{I}=0.0025 \mathrm{kmol} / \mathrm{m}^{3}$.

\begin{tabular}{cc}
\hline Run No. & Crystal Size $(\mu \mathrm{m})$ \\
\hline$\triangle$ R un A -2-2-M 14 & 460 \\
$\square$ R un A -4-2-0 13 & 650 \\
R un A -4-1-0 20 & 920 \\
\hline
\end{tabular}

The mass transfer between fluidized spheres and liquid solution has been widely studied in many operations, such as dissolution, crystallization, ion exchange, leaching, and adsorption. Numerous correlations to estimate the mass-transfer coefficient are proposed in the literature and summarized by Tournie et al. (1997). However, none of them is derived from or applied to the crystal growth of a barely soluble system. O ne of the correlations originally proposed by $F$ an and modified by Kunii and Levenspiel (1969) for a liquid fluidized bed with low voidage has the following form when neglecting the diffusion term:
Table 2. M ass-Transfer and Surface-Reaction Coefficients of Calcite Crystal Estimated by Using Eq. 14 at $\mathrm{pH}=9.5$ and $\mathrm{I}=0.0025 \mathrm{kmol} / \mathrm{m}^{3}$

\begin{tabular}{lcccc}
\hline & $\begin{array}{c}\text { Particle } \\
\text { Size } \\
(\mu \mathrm{m})\end{array}$ & $\begin{array}{c}\text { Superficial } \\
\text { Velocity } \\
(\mathrm{m} / \mathrm{s})\end{array}$ & $\begin{array}{c}\mathrm{K}_{\mathrm{d}} \\
\left(10^{-10} \mathrm{~m} / \mathrm{s}\right)\end{array}$ & $\begin{array}{c}\mathrm{K}_{\mathrm{r}} \\
\left(10^{-9} \mathrm{~m} / \mathrm{s}\right)\end{array}$ \\
\hline A un N 0. & 920 & 3.54 & 1.45 & 13.78 \\
A-4-1-0 20 2013 & 650 & 3.54 & 1.42 & 2.25 \\
A-2-2-M 14 & 460 & 3.54 & 1.33 & 0.30 \\
A-1-4-M 08,16 & 460 & 2.36 & 1.11 & 0.31 \\
A-2-4-M 12,13 & 460 & 1.42 & 1.29 & 0.34 \\
\hline
\end{tabular}

$$
\operatorname{Sh}\left(\frac{\mathrm{K}_{\mathrm{d}} \mathrm{L}}{\mathrm{D}}\right)=1.5\left[(1-\epsilon) \mathrm{Re}_{\mathrm{p}}\right]^{1 / 2} \mathrm{Sc}^{1 / 3}, \quad \epsilon \leq 0.84
$$

and

$$
\operatorname{Re}_{\mathrm{p}}=\frac{\mathrm{Lu} \rho}{\mu}, \quad 5<\mathrm{Re}_{\mathrm{p}}<120,
$$

where $u$ is the superficial velocity and $\epsilon$ the bed voidage. Equation 15 is derived by using the experimental data of $\beta$ naphthol and benzoic acid, which are soluble systems. To test the applicability of Eq. 15 to a barely soluble salt, calcite, the diffusivity of calcite in water should be found first. U nfortunately, the diffusivity data of calcite are not available in the literature, and the existing correlations for predicting diffusivity are only good for dilute solutions, which is quite different from the supersaturated solution we are dealing with.

A lthough a correlation to predict the mass-transfer coefficient could not be established for the calcite growth, Eq. 15 is used to test the consistency of the mass-transfer coefficient as shown in Table 2 . V alues of $\left[(1-\epsilon) \mathrm{Re}_{\mathrm{p}}\right]^{1 / 2}$ for crystals of 460, 650 and $920 \mu \mathrm{m}$, fluidized at various superficial velocities, are tabulated in Table 3. The values of $\left[(1-\epsilon) \mathrm{Re}_{\mathrm{p}}\right]^{1 / 2}$ at various superficial velocities are quite constant for each of the sizes. Therefore an average value is calculated for each size in Table 3. A ccording to Eq. 15, the mass-transfer coefficient is proportional to $\left[(1-\epsilon) \operatorname{Re}_{p}\right]^{1 / 2} / \mathrm{L}$. The ratios of $[(1-$ $\left.\epsilon) \operatorname{Re}_{\mathrm{p}}\right]^{1 / 2} /$ to that of $920 \mu \mathrm{m}$ are shown in the last column

\begin{tabular}{|c|c|c|c|c|c|c|}
\hline $\begin{array}{l}\text { Particle } \\
\text { Size, L } \\
(\mu \mathrm{m})\end{array}$ & $\begin{array}{l}\text { Superficial } \\
\text { Velocity } \\
(\mathrm{m} / \mathrm{s})\end{array}$ & $\begin{array}{l}\text { Bed } \\
\text { Voidage } \\
\epsilon\end{array}$ & $\mathrm{Re}_{\mathrm{p}}$ & {$\left[(1-\epsilon) \mathrm{Re}_{\mathrm{p}}\right]^{1 / 2}$} & $\begin{array}{c}{\left[(1-\epsilon) \mathrm{Re}_{\mathrm{p}}\right]^{1 / 2}} \\
\text { A verage }\end{array}$ & $\frac{\left[(1-\epsilon) \operatorname{Re}_{p}\right]^{1 / 2} \Lambda}{\left\{\left[(1-\epsilon) \operatorname{Re}_{p}\right]^{1 / 2} \Lambda\right\}_{L=920 \mu \mathrm{m}}}$ \\
\hline 460 & $\begin{array}{l}1.42 \\
2.36 \\
3.54 \\
4.72\end{array}$ & $\begin{array}{l}0.68 \\
0.77 \\
0.84 \\
0.91\end{array}$ & $\begin{array}{r}7.14 \\
12.05 \\
18.08 \\
24.11 \\
\end{array}$ & $\begin{array}{l}1.52 \\
1.67 \\
1.67 \\
1.44 \\
\end{array}$ & 1.57 & 0.97 \\
\hline 650 & $\begin{array}{l}1.42 \\
2.36 \\
2.81 \\
3.54 \\
4.72\end{array}$ & $\begin{array}{l}0.50 \\
0.58 \\
0.64 \\
0.71 \\
0.79\end{array}$ & $\begin{array}{l}10.23 \\
17.06 \\
20.46 \\
25.55 \\
34.11\end{array}$ & $\begin{array}{l}2.26 \\
2.67 \\
2.71 \\
2.72 \\
2.68\end{array}$ & 2.61 & 1.13 \\
\hline 920 & $\begin{array}{l}1.42 \\
2.81 \\
3.54 \\
4.72\end{array}$ & $\begin{array}{l}0.60 \\
0.64 \\
0.70 \\
0.77\end{array}$ & $\begin{array}{l}24.17 \\
29.00 \\
36.11 \\
47.20\end{array}$ & $\begin{array}{l}3.11 \\
3.22 \\
3.29 \\
3.31\end{array}$ & 3.23 & 1 \\
\hline
\end{tabular}

Table 3. Values of $\left[(1-\epsilon) \operatorname{Re}_{\mathrm{p}}\right]^{1 / 2}$ for Different Sizes of Calcite Fluidized at Various Superficial Velocities 
of Table 3. Thus, the ratios of the mass-transfer coefficient for the three sizes are:

$$
\frac{\left(K_{d}\right)_{L=460 \mu \mathrm{m}}}{0.97}=\frac{\left(K_{d}\right)_{L=650 \mu m}}{1.13}=\frac{\left(K_{d}\right)_{L=920 \mu m}}{1.0}
$$

The ratios are rather constant, meaning that the masstransfer coefficient of calcite growth in a fluidized bed is independent of crystal size and superficial velocity. This result is consistent with Table 2.

The surface-reaction coefficients at various crystal sizes are also listed in Table 2, which increases with crystal size and are rather constant for the same size. The size-dependent $K_{r}$ is responsible for the effect of particle size on the calcite growth rate shown in Figure 11. Similar results have been reported for calcite growth in a stirred tank (Tai et al., 1993) and potassium alum in a fluidized bed (Budz et al., 1984; Tai et al., 1987). In Table 2 we also note that the values of $K_{r}$ are higher than those of $\mathrm{K}_{\mathrm{d}}$, especially for larger sizes. It is interesting to see if there is a controlling step for the calcite growth, which can be judged from the surface-reaction effectiveness factor $\eta$ (Garside, 1971) or the ratio of $\sigma_{2-} / \sigma$. If $\eta$ or $\sigma_{2-} / \sigma$ approaches 1 , the crystal growth process is surface-reaction control. On the other hand, if $\eta$ or $\sigma_{2-} / \sigma$ approaches 0 , the growth process is mass-transfer control. The calculated values of $\eta$ and $\sigma_{2-} / \sigma$ range between 0.191 and 0.355 , and 0.433 and 0.577 , respectively, for the experimental run $\mathrm{A}-2-2-\mathrm{M} \mathrm{14}$, in which the mass-transfer resistance is the lowest among the experimental runs shown in Table 2 as judged from the relative magnitude of $K_{d}$ to $K_{r}$. Therefore, the mass-transfer resistance and surface-reaction resistance are both significant, with the former being higher than the later in a fluidized bed operated at $\mathrm{pH} 9.5$ and an ionic strength $0.0025 \mathrm{kmol} / \mathrm{m}^{3}$. For the largest size of $920 \mu \mathrm{m}$, the growth is almost mass-transfer controlled.

\section{Growth-rate expression of calcite crystals}

Once the surface-reaction order, mass-transfer coefficient, and surface-reaction coefficient are available, the crystal growth rate can be expressed according to the two-step model. For a surface-reaction order $r=2$, the expression of crystal growth rate is as follows (M ullin, 1993):

$$
G=K_{d}\left[\left(1+\frac{K_{d}}{2 K_{r} \sigma}\right)-\sqrt{\left\{\left(1+\frac{K_{d}}{2 K_{r} \sigma}\right)^{2}-1\right\}}\right] \sigma
$$

The values of $\mathrm{K}_{\mathrm{d}}$ and $\mathrm{K}_{\mathrm{r}}$ can be determined from the experiment using a lab-scale fluidized bed. Because $K_{d}$ is almost a constant, which is independent of crystal size and superficial velocity, and $\mathrm{K}_{\mathrm{r}}$ is related to crystal surface properties, which should be independent of hydrodynamics, the experimental data of $K_{d}$ and $K_{r}$ obtained in a lab-scale apparatus can be used for scale-up purposes.

The units of crystal growth rate, G, in Eq. 18 is in $\mathrm{m} / \mathrm{s}$. The linear growth rate can be easily converted to mass growth rate or molar growth rate, such as in Eq. 1, by using Eqs. 9 and 10. Equation 18, which is based on the two-step growth model, is more able than Eq. 1, which is an overall growth-rate equation, to represent the crystal-growth-rate expression of calcite.

\section{Conclusion}

The metastable region of the $\mathrm{CaCl}_{2}-\mathrm{Na}_{2} \mathrm{CO}_{3}-\mathrm{H}_{2} \mathrm{O}$ system is explored in this study. The solubility and supersolubility curves, which are the boundaries of the metastable region, are almost parallel straight lines in the concentration range studied, when the precipitation diagram is constructed by

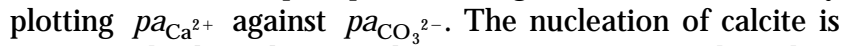
suppressed when the growth experiments are conducted in the metastable region, using a fluidized-bed crystallizer.

Factors that affect the calcite growth rate in a dense fluidized bed are identified, including supersaturation, $\mathrm{pH}$, ionic strength, and particle size and type of seeds. On the other hand, the effects of superficial velocity on growth rate are less significant. An induction period for crystal growth is required for the silica-sand seed, which is one of the seeding materials used in a large-scale water-softening pellet reactor. The growth rate of this type of seed is slower before the seed surface is fully covered with calcite.

When the calcite-growth-rate data of constant $\mathrm{pH}$ and ionic strength are analyzed by the two-step growth model, the mass-transfer coefficients so obtained are independent of crystal size and superficial velocity. On the other hand, the surface-reaction coefficient is size dependent. Since the mass-transfer and surface-reaction coefficients are rather insensitive to hydrodynamics in a fluidized bed, a growth-rate equation can be given for design purposes according to the two-step growth model, in which the mass-transfer coefficient and surface-reaction coefficient are determined using a labscale fluidized bed.

\section{Acknowledgment}

The authors gratefully acknowledge the financial support of the $\mathrm{N}$ ational Science Council of R epublic of China.

\section{Notation}

$\left[\mathrm{Ca}^{2+}\right]=$ calcium-ion concentration, $\mathrm{kmol} / \mathrm{m}^{3}$

$[\mathrm{Ca}]_{T}=$ total calcium concentration, $\mathrm{kmol} / \mathrm{m}^{3}$

$\left[\mathrm{CO}_{3}{ }^{2-}\right]=$ carbonate-ion concentration, $\mathrm{kmol} / \mathrm{m}^{3}$

$\left[\mathrm{CO}_{3}\right]_{T}=$ total carbonate concentration, $\mathrm{kmol} / \mathrm{m}^{3}$

$\mathrm{D}=$ diffusivity, $\mathrm{m}^{2} / \mathrm{s}$

$\mathrm{G}=$ linear crystal growth rate, $\mathrm{m} / \mathrm{s}$

$\mathrm{I}=$ ionic strength, $\mathrm{kmol} / \mathrm{m}^{3}$

$\mathrm{K}_{\mathrm{r}}=$ surface-reaction coefficient, $\mathrm{m} / \mathrm{s}$

$\mathrm{L}=$ crystal size, $\mathrm{m}$

$\mathrm{Re}_{\mathrm{p}}=$ particle $\mathrm{R}$ eynolds number

$\mathrm{Sc}=$ Schmidt number

$\mathrm{Sh}=$ Sherwood number

$\mathrm{T}=$ temperature, ${ }^{\circ} \mathrm{C}$

$\mathrm{t}=$ time, $\mathrm{s}$

$\mu=$ solution viscosity, $\mathrm{kg} / \mathrm{ms}$

$\rho=$ solution density, $\mathrm{kg} / \mathrm{m}^{3}$

$\sigma_{2-}=$ interfacial relative supersaturation

\section{Literature Cited}

A STM Designation D 513, p. 416 (1974).

Budz, J., P. H. Karpinski, and Z. Nuruc, "Influence of H ydrodynamics on Crystal Growth and Dissolution in a Fluidized Bed," AIChE J., 30, 710 (1984).

Chen, C.-Y.." "Crystal Growth Kinetics of Calcium Carbonate in a Fluidized Bed," M S Thesis, N ational Taiwan U niv., Taipei (1995). 
Dirken, P., E. Baars, A. G raveland, and C. F. Woensdregt, "On the Crystallization of Calcite $\left(\mathrm{CaCO}_{3}\right)$ D uring the Softening Process of D rinking W ater in a Pellet R eactor with Fluidized Beds of Q uartz, Garnet and Calcite Seeds," Industrial Crystallization 90, A. Mersmann, ed., Garmisch-Partenkirchen, FR G, p. 95 (1990).

Furedi-M ilhofer, H., E. Oljica-Zabcic, B. Purgaric, B. Kosar-Grasic, and N. Pavkovic, "Precipitation of Calcium Phosphates from Electrolyte Solutions," J. Inorg. Nucl. Chem., 37, 2047 (1975).

Garside, J., "The Concept of Effectiveness Factors in Crystal Growth," Chem. Eng. Sci., 26, 1425 (1971).

Kralj, D., L. B recevic, and A. E. N ielsen, "V aterite G rowth and Dissolution in Aqueous Solution. I. Kinetics of Crystal Growth," J. Cryst. G rowth, 104, 793 (1990).

Kunii, D., and $O$. Levenspiel, Fluidization Engineering, Wiley, New Y ork, p. 197 (1969).

Levenspiel, 0 ., Chemical Reaction Engineering, 2nd ed., Wiley, New Y ork, p. 272 (1972).

Mullin, J. W., Crystallization, 3rd ed., Butterworth-H einemann, Oxford, p. 209 (1993).

Nancollas, G. H., Interactions in Electrolyte Solutions, Elsevier, A msterdam (1966).

Nielsen, A . E ., and J. M. T oft, "E lectrolyte Crystal G rowth Kinetics," J. Cryst. G rowth, 67, 278 (1984).

R eed, J. S., Introduction to the Principles of Ceramic Processing, Wiley, Singapore, p. 134 (1989).

Seckler, M. M., O. S. L. Bruinsma, G. M. van Rosmalen, J. C. van Dijk, and F. Delgorge, "Phosphate Removal by Means of a Full Scale Pellet Reactor," Industrial Crystallization 90, A. M ersmann, ed., G armisch-Partenkirchen, FR G, p. 143 (1990).

Söhnel, O., and J. Garside, Precipitation-Basic Principles and Industrial Applications, Butterworth-H einemann, Boston, p. 149 (1992).
Stubicar, N., M. Scrbak, and M. Stubicar, "Crystal G rowth of Lead Fluoride U sing the Constant Composition M ethod: II. The Effect of $\mathrm{Pb} / \mathrm{F}$ A ctivity R atio on the Kinetics of Crystal G rowth," J. Cryst. Growth, 100, 261 (1990).

Stubicar, N., B. M arkovic, A. Tonejc, and M. Stubicar, "Crystal $G$ rowth of L ead Fluoride $U$ sing the Constant Composition M ethod: III. Effect of pH and Ionic Strength," J. Cryst. G rowth, 130, 300 (1993).

Tai, C. Y ., and R. K. Pan, "G rowth Kinetics of Copper Sulfate Pentahydrate Crystal in Pure and Impure Systems,"J . Chin. Inst. Chem. Eng., 16, 379 (1985).

Tai, C. Y., C.-Y. Chen, and J.-F. Wu, "Crystal Dissolution and Growth in a Lean Fluidized-Bed Crystallizer," Chem. Eng. Commun., 56, 329 (1987).

Tai, C. Y., P. C. Chen, and S. M. Shih, "Size-D ependent G rowth and Contact Nucleation of Calcite Crystals," AIChE J., 39, 1472 (1993).

Tai, C. Y., "Crystallization Kinetics Revealed from Experimental Data A nalyzed by the Two-Step Growth Model," J. Chem. Eng. (Jpn.), 30, 373 (1997).

Tournie, P., C. Larguerie, and J. P. Couderc, "Correlations for M ass Transfer Between Fluidized Spheres and a Liquid," Chem. Eng. Sci., 34, 1247 (1979).

Van Dijk, J. C., and D. A. Wilms, "Water Treatment Without Waste M aterial-Fundamentals and State of the A rt of Pellet Softening," J. Water SRT-Aqua, 40, 263 (1991).

Manuscript received N ov. 5, 1998, and revision received May 3, 1999. 